\title{
MEDIUM OPTIMIZATION FOR THE PRODUCTION OF BIOMASS BY Cunninghamella sp. 2A1 USING RESPONSE SURFACE METHODOLOGY
}

\author{
Siti Aminah Sulaiman, Aidil Abdul Hamid*, Wan Mohtar Wan Yusoff \\ School of Biosciences and Biotechnology, Faculty of Science and Technology, \\ Universiti Kebangsaan Malaysia, 43600 Bangi, Selangor, Malaysia
}

Received 15 June 2005

\begin{abstract}
A statistical design approach has been used to optimize the production of biomass by Cunninghamella sp. 2A1, evaluated based on lipidless biomass. A $2^{3}$ full factorial central composite design (CCD) was chosen to study the combined effects of three factors; ammonium tartrate, peptone and glucose concentrations. The p-value for each factors was $<0.05$ suggesting that these factors have significant effect on the production of lipidless biomass. The production is represented by a linear model with $\mathrm{p}$-value $<0.0001$. The optimized medium consists of 3.86 $\mathrm{g} / 1$ ammonium tartrate, $55.84 \mathrm{~g} / 1$ glucose and $7.73 \mathrm{~g} / 1$ peptone predicted $16.83 \mathrm{~g} / 1$ lipidless biomass. Results from four replications based on the optimized medium produced $18.48 \mathrm{~g} / \mathrm{l}$ lipidless biomass, which are in close agreement with the predicted value. The coefficient for glucose was the highest indicating it as the most significant factor affecting lipidless biomass production.
\end{abstract}

Keywords: Medium optimization, Cunninghamella sp. 2A1, Biomass, Response surface.

\section{INTRODUCTION}

Polyunsaturated fatty acids (PUFA) play an important role as precursors for a variety of metabolites (such as prostaglandins and leukotrienes) that regulate critical biological functions. The first commercial-scale microbial lipid production was developed in 1985 in the United Kingdom using Mucor circinelloides, an oleaginous fungus producing lipid containing 15 - 18\% $\gamma$-linolenic acid (GLA) (of total fatty acid) [1]. Production of lipid is very much dependent on medium composition and for a new isolate, this aspect needs intensive investigation especially in relation to biomass concentration and lipid content. Our preliminary data involving the investigation of four medium components (ammonium tartrate, peptone, yeast extract and glucose) indicated that ammonium tartrate, peptone and glucose affect the biomass production of Cunninghamella sp. 2A1 (unpublished data). Therefore, these three factors were chosen for further optimization for biomass production using response surface methodology (RSM).

*Corresponding author e-mail: aidilah@pkrisc.cc.ukm.my 
Optimization of media are normally carried out by varying one parameter at a time whilst keeping the others constant. RSM is a technique for studying the effect of several factors acting together and affecting the responses by varying them in a number of experiments [2]. RSM had been successfully applied in the optimization of medium composition for the production of glucosyltransferase by Aspergillus niger [3], optimization of growth medium for the production of CGTase from Bacillus sp. [4,5] and optimization of culture medium for production of lovastatin by Monascus ruber [6].

This study reports the application of RSM to optimize biomass production using oleaginous GLA-producing local fungal isolate, Cunninghamella sp. 2A1. The assessment of the actual biomass concentration was carried out based on lipidless biomass as lipid content contributed up to $30 \%(\mathrm{w} / \mathrm{w})$ of biomass. The relationship between the selected factors (concentrations of ammonium tartrate, glucose and peptone), and their interactions and influences on the measured responses were established.

\section{METHODOLOGY}

\subsection{Microorganism and culture condition}

Cunninghamella sp. 2A1 was obtained from the School of Biosciences and Biotechnology, Faculty of Science and Technology, Universiti Kebangsaan Malaysia, Bangi, Selangor, Malaysia. The cultures were maintained at $4{ }^{\circ} \mathrm{C}$ and were subcultured at regular intervals. Inoculum was prepared by transferring $1 \mathrm{ml}$ of spore suspension into $100 \mathrm{ml}$ of nitrogen-limited medium [7] and incubated at $30^{\circ} \mathrm{C}, 250 \mathrm{rpm}$ for $48 \mathrm{~h}$. The composition $(\mathrm{g} / \mathrm{l})$ of medium comprises: ammonium tartrate, $1.0 ; \mathrm{KH}_{2} \mathrm{PO}_{4}, 7.0 ; \mathrm{Na}_{2} \mathrm{HPO}_{4}, 2.0 ; \mathrm{MgSO}_{4} .7 \mathrm{H}_{2} \mathrm{O}, 1.5$; yeast extract, $1.5 ; \mathrm{CaCl}_{2}, 0.1 ; \mathrm{FeCl}_{3} .6 \mathrm{H}_{2} \mathrm{O}, 0.008 ; \mathrm{ZnSO}_{4} .7 \mathrm{H}_{2} \mathrm{O}, 0.0001 ; \mathrm{CuSO}_{4} .5 \mathrm{H}_{2} \mathrm{O}, 0.0001$; $\mathrm{Co}\left(\mathrm{NO}_{3}\right)_{2} .6 \mathrm{H}_{2} \mathrm{O}, 0.0001 ; \mathrm{MnSO}_{4} .5 \mathrm{H}_{2} \mathrm{O}, 0.0001$. Glucose, $30 \mathrm{~g} / 1$ was sterilized $\left(121^{\circ} \mathrm{C}\right.$ for 15 $\mathrm{min}$ ) and added separately.

A $10 \%(\mathrm{v} / \mathrm{v})$ of the seed culture was used as inoculum for batch fermentation in a $500 \mathrm{ml}$ flask containing $100 \mathrm{ml}$ of medium. Medium composition was varied based on the experimental design using Design Expert Version 6.0.10 (Section 2.3.). Cultivation was then carried out at $250 \mathrm{rpm}$ and $30^{\circ} \mathrm{C}$ for $120 \mathrm{~h}$. Cultures were harvested after $120 \mathrm{~h}$ of fermentation and the biomass concentration and lipid content were determined.

\subsection{Analytical methods}

\subsubsection{Determination of cell dry weight}

Biomass was harvested by filtering a $100 \mathrm{ml}$ of the culture through a filter paper (Whatman No.1), washed extensively with distilled water and freeze-dried for $24 \mathrm{~h}$. The dry weight of cell was determined (AND GR-200, A\&D Measurement (M) Sdn. Bhd.). Lipidless biomass was calculated by subtracting the amount of lipid per litre culture from the biomass produced per litre culture. 


\subsubsection{Determination of ammonium tartrate and glucose concentration}

Ammonium tartrate concentration was measured using indophenol method [8]. The glucose concentration was determined using a glucose oxidase Perid-test kit (Boehringer Mannheim). The optical density (OD) for ammonium tartrate and glucose determination was carried out at $625 \mathrm{~nm}$ and $500 \mathrm{~nm}$ (JASCO UV-VIS Spectrophotometer), respectively.

\subsubsection{Extraction of lipid}

Lipid was extracted using chloroform and methanol in a ratio of 2:1 (v/v) [9] overnight before filtering. The filtrate was washed with $150 \mathrm{ml}$ of $\mathrm{NaCl}(1 \%)$ followed by $150 \mathrm{ml}$ of distilled water. The chloroform layer was obtained and evaporated using rotary evaporator (BUCHI Rotavapor R-124). Lipid residue was dissolved in a minimal amount of diethyl ether and transferred to a tared vial.

\subsection{Experimental design}

Experimental design was determined using Design Expert Software Version 6.0.10 (State-Ease Inc., Minneapolis, USA). A 2 [3] full factorial CCD for three independent factors with six replication of the central points and six axial points, leading to a total of 20 sets of experiments. Low and high factor settings were coded as -1 and +1 respectively, the centre points was coded as 0 and the design is extended up to $+\alpha$ and $-\alpha(\alpha=1.682)$ (Table 1). The value of alpha represents the distance from the centre of the design space to an axial. The optimal concentrations of factors were obtained by a numerical optimization procedure and analysing the response surface plots [10].

Table 1: Factor settings in the form of coded values

\begin{tabular}{|c|c|c|c|c|c|c|}
\hline \multirow{2}{*}{\multicolumn{2}{|c|}{ Factors }} & \multicolumn{5}{|c|}{ Level of factors } \\
\hline & & $-\alpha$ & -1 & 0 & +1 & $+\alpha$ \\
\hline \multicolumn{2}{|c|}{ Ammonium tartrate $\left(X_{1}, g / l\right)$} & 1.32 & 2 & 3 & 4 & 4.68 \\
\hline Glucose & $\left(\mathrm{X}_{2,}, \mathrm{~g} / \mathrm{l}\right)$ & 23.18 & 30 & 40 & 50 & 56.82 \\
\hline Peptone & $\left(\mathrm{X}_{3}, \mathrm{~g} / \mathrm{l}\right)$ & 2.64 & 4 & 6 & 8 & 9.32 \\
\hline
\end{tabular}

From the experimental results, an approximate polynomial relationship for dependent factors of lipidless biomass production was obtained. The result of this design was used to fit a first-order model,

$$
Y=\beta_{0}+\sum_{i=1}^{k} \beta_{i} x_{i}
$$

$\mathrm{Y}$ is the predicted response; $\beta_{0}, \beta_{\mathrm{i}}$, are the constant coefficient, and $\mathrm{X}_{\mathrm{i}}$ is the coded independent factors. 


\section{RESULTS AND DISCUSSION}

Table 2 shows the predicted, actual and residual values of twenty runs. The results showed that the predicted values closely matched the actual values.

Table 2: $\quad$ Experimental design of 20 runs of $2^{3}$ full factorial CCD with predicted, actual and residual values of each runs

\begin{tabular}{|c|c|c|c|c|c|c|}
\hline \multirow{3}{*}{ Run } & \multicolumn{3}{|c|}{ Factors } & \multirow{2}{*}{\multicolumn{3}{|c|}{$\frac{\text { Response }}{\text { Lipidless biomass (g/l) }}$}} \\
\hline & \multirow{2}{*}{$\mathrm{X}_{1}(\mathrm{~g} / \mathrm{l})$} & \multirow{2}{*}{$\mathrm{X}_{2}(\mathrm{~g} / \mathrm{l})$} & \multirow{2}{*}{$\mathrm{X}_{3}(\mathrm{~g} / \mathrm{l})$} & & & \\
\hline & & & & Actual & Predicted & Residual \\
\hline 1 & -1 & -1 & -1 & 9.89 & 9.11 & 0.78 \\
\hline 2 & +1 & -1 & -1 & 9.68 & 10.12 & -0.44 \\
\hline 3 & -1 & +1 & -1 & 12.85 & 13.37 & -0.52 \\
\hline 4 & +1 & +1 & -1 & 14.72 & 14.37 & 0.35 \\
\hline 5 & -1 & -1 & +1 & 10.91 & 10.50 & 0.41 \\
\hline 6 & +1 & -1 & +1 & 11.10 & 11.50 & -0.40 \\
\hline 7 & -1 & +1 & +1 & 14.69 & 14.76 & -0.07 \\
\hline 8 & +1 & +1 & +1 & 15.37 & 15.76 & -0.39 \\
\hline 9 & $-\alpha$ & 0 & 0 & 11.51 & 11.59 & -0.08 \\
\hline 10 & $+\alpha$ & 0 & 0 & 14.07 & 13.28 & 0.79 \\
\hline 11 & 0 & $-\alpha$ & 0 & 8.67 & 8.86 & -0.19 \\
\hline 12 & 0 & $+\alpha$ & 0 & 16.40 & 16.01 & 0.39 \\
\hline 13 & 0 & 0 & $-\alpha$ & 11.28 & 11.27 & 0.01 \\
\hline 14 & 0 & 0 & $+\alpha$ & 13.98 & 13.60 & 0.38 \\
\hline 15 & 0 & 0 & 0 & 12.11 & 12.44 & -0.33 \\
\hline 16 & 0 & 0 & 0 & 10.25 & 12.44 & -2.19 \\
\hline 17 & 0 & 0 & 0 & 13.34 & 12.44 & 0.90 \\
\hline 18 & 0 & 0 & 0 & 12.43 & 12.44 & -0.01 \\
\hline 19 & 0 & 0 & 0 & 13.06 & 12.44 & 0.62 \\
\hline 20 & 0 & 0 & 0 & 12.40 & 12.44 & -0.04 \\
\hline
\end{tabular}




\subsection{Model selection}

Table 3 shows the sequential model sum of squares for the lipidless biomass to show how terms of increasing complexity contribute to the total model. From that, the linear coefficient showed significant result ( $\mathrm{p}$-value $<0.0001$ ) and the model is not aliased. P-value for two-factor interaction (2FI), quadratic and cubic terms for lipidless biomass were $>0.05$, meaning that the interactions among factors were not significant. This indicates that the linear model was accurate in describing or predicting the pattern of significant to the production of lipidless biomass from Cunninghamella sp. $2 \mathrm{~A} 1$.

Table 3: $\quad$ Sequential model sum of squares for lipidless biomass $(\mathrm{g} / \mathrm{l})$

\begin{tabular}{lcccccc}
\hline Source & $\begin{array}{c}\text { Sum of } \\
\text { squares }\end{array}$ & $\begin{array}{c}\text { Degrees of } \\
\text { freedom }\end{array}$ & $\begin{array}{c}\text { Mean } \\
\text { square }\end{array}$ & F-value & P-value & \\
\hline Mean & 2992.80 & 1 & 2992.80 & & & \\
Linear & 71.78 & 3 & 23.93 & 97.18 & $<0.0001$ & Suggested \\
2FI & 0.90 & 3 & 0.30 & 1.30 & 0.3207 & \\
Quadratic & 0.18 & 3 & 0.059 & 0.20 & 0.8920 & \\
Cubic & 1.37 & 4 & 0.34 & 1.38 & 0.3611 & Aliased \\
Residual & 1.24 & 5 & 0.25 & & & \\
Total & 3068.28 & 19 & 161.49 & & & \\
\hline
\end{tabular}

* 2FI - 2-factor interaction

\subsection{Model fitting}

ANOVA were used to evaluate the adequacy of the fitted model (Table 4). The fisher F-test with a very low probability value $(<0.0001)$ for response (lipidless biomass) demonstrated a high significance for the regression model. The goodness of fit of the model was checked by the determination coefficient $\left(\mathrm{R}^{2}\right)$ [11]. The R-squared value provided a measure of the variability in the actual response values could be explained by the experimental factors and their interactions. A value of one represents the ideal case at which $100 \%$ of the variation in the observed value can be explained by the model [12]. In this case, the value of $\mathrm{R}^{2}$ for lipidless biomass was 0.9511 indicates that only $4.89 \%$ of the total variations was not explained by the model.

The value of the adjusted $\mathrm{R}^{2}$ is also high, which indicates a high significance of the model. A higher value of the correlation coefficient $(\mathrm{R}=0.9752)$ signifies an excellent correlation between the independent factors. An insignificant lack of fit indicated that the model fits the data. The lack of fit tests compares the residual error to the pure error from replicated design 
points. The lack of fit F-value of 0.24 for lipidless biomass implies it is not significant relative to the pure error. On the other hand, a non-significant lack of fit represents a good model which fit the data.

Table 4: $\quad$ ANOVA for response surface linear model for lipidless biomass (g/l) after $120 \mathrm{~h}$ fermentation

\begin{tabular}{lccccc}
\hline \multicolumn{1}{c}{ Source } & $\begin{array}{c}\text { Sum of } \\
\text { squares }\end{array}$ & $\begin{array}{c}\text { Degrees of } \\
\text { freedom }\end{array}$ & $\begin{array}{c}\text { Mean } \\
\text { square }\end{array}$ & F-value & P-value \\
\hline Model & 71.78 & 3 & 23.93 & 97.18 & $<0.0001$ \\
Ammonium tartrate & 3.42 & 1 & 3.42 & 13.89 & 0.0020 \\
Glucose & 61.79 & 1 & 61.79 & 250.97 & $<0.0001$ \\
Peptone & 6.57 & 1 & 6.57 & 26.67 & 0.0001 \\
Residual & 3.69 & 15 & 0.25 & & \\
Lack of Fit & 2.65 & 11 & 0.24 & 0.92 & 0.5897 \\
Pure Error & 1.05 & 4 & 0.26 & & \\
Correlation Total & 75.48 & 18 & & & \\
\hline
\end{tabular}

$\mathrm{R}^{2}=0.9511, \mathrm{R}=0.9752$, Adjusted $\mathrm{R}^{2}=0.9413 ;$ *significance $(\%)=\mathrm{p}<0.05$.

The regression equation:

Lipidless biomass $(\mathrm{g} / \mathrm{l})=12.55+0.50 \mathrm{X}_{1}+2.13 \mathrm{X}_{2}+0.69 \mathrm{X}_{3}$.

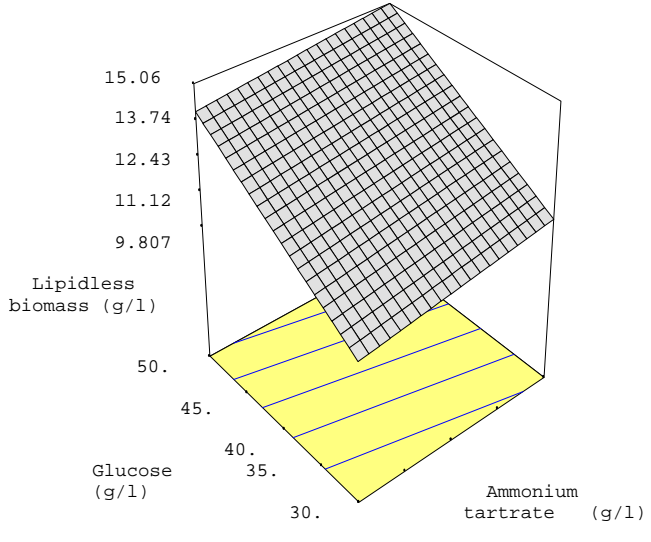

Fig. 1: Effect of glucose and ammonium tartrate concentration on the lipidless biomass by Cunninghamella sp. $2 \mathrm{~A}$

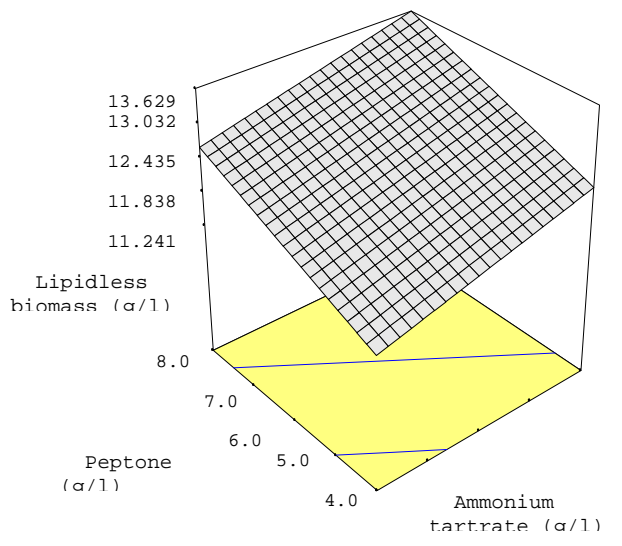

Fig. 2: Effect of peptone and ammonium tartrate concentration on the lipidless biomass by Cunninghamella sp. $2 A 1$ 


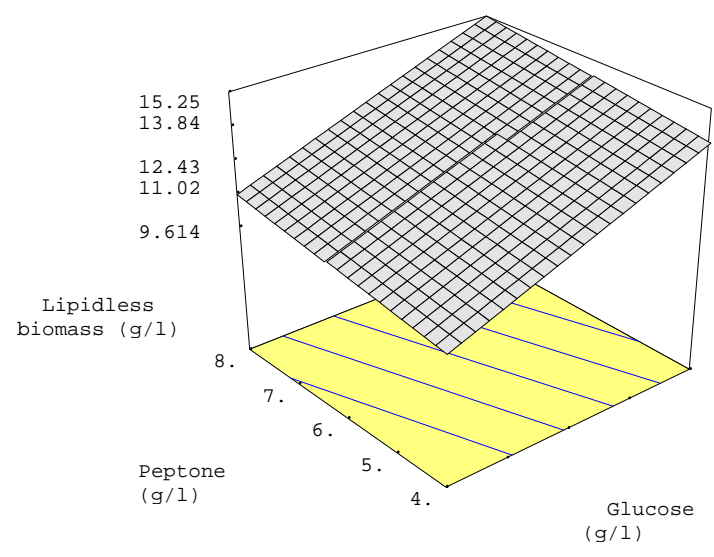

Fig. 3: Effect of peptone and glucose concentration on the lipidless biomass by Cunninghamella sp. 2A1

Based on Table 4, the concentration of ammonium tartrate, glucose and peptone are significant factors $(\mathrm{p}<0.05)$ affecting lipidless biomass. Generally, nitrogen and carbon sources are required for biomass production [13]. The regression equation of the model for lipidless biomass in terms of coded values showed significant positive linear effects for all three factors. Our previous study showed that increasing the concentration of ammonium tartrate in medium led to an increase in biomass concentration (unpublished data). From the regression equation, it predicted that increasing the concentrations of ammonium tartrate $\left(\mathrm{X}_{1}\right)$, glucose $\left(\mathrm{X}_{2}\right)$ and peptone $\left(\mathrm{X}_{3}\right)$ should enhance lipidless biomass production. The factor with the largest effect was the $\mathrm{X}_{2}$ (glucose) and followed by the $\mathrm{X}_{3}$ (peptone).

Figure 1 - 3 shows the three-dimensional surface plots for the lipidless biomass, as a function of concentrations of two factors with the other one being at their zero level. As can be seen, an increase in ammonium tartrate, glucose and peptone led to an increase in lipidless biomass production.

\subsection{Numerical optimization of factors}

Based on Table 2 (run no.12), the highest concentration of lipidless biomass (16.4 g/l) from Cunninghamella sp. 2A1 was obtained when the concentration of ammonium tartrate, glucose and peptone were $3.0,56.82$ and $6.0 \mathrm{~g} / 1$, respectively. To obtain the maximum optimum activity, the factor levels and response were set at the desired goal using Design Expert's Numerical Optimization under desirability equal to one. Optimal concentration of ammonium tartrate, glucose and peptone was established at $3.86 \mathrm{~g} / 1,55.84 \mathrm{~g} / 1$ and $7.73 \mathrm{~g} / \mathrm{l}$, respectively. This solution gives the predicted response for lipidless biomass at $16.83 \mathrm{~g} / \mathrm{l}$. From four replications of experiment, lipidless biomass at $18.48 \mathrm{~g} / \mathrm{l}$ was achieved. The results coincide with the predicted value and the model was proven to be adequate. 


\section{CONCLUSION}

$\mathrm{CCD}$ and response surface methodology were useful to determine the optimum levels of medium components concentration that significantly influence the production of lipidless biomass from Cunninghamella sp. 2A1. The final composition of the defined medium to produce $18.48 \mathrm{~g} / 1$ of lipidless biomass after the optimization procedure was as follows: $3.86 \mathrm{~g} / 1$ ammonium tartrate; glucose $55.84 \mathrm{~g} / 1$ and peptone $7.73 \mathrm{~g} / 1$.

\section{ACKNOWLEDGEMENTS}

The authors would like to thank the Ministry of Science, Technology and Innovation, Malaysia for financial supported under IRPA 09-02-02-001 (BTK/TD/001).

\section{REFERENCES}

1. Ratledge, C. (1992), Microbial lipids: commercial realities or academic curiosities, In: Kyle, D.J. and Ratledge, C. (Eds.), Industrial applications of single cell oils, AOCS Press, Champaign, pp. 1-14.

2. Maddon, I.S. and Richard, S.H. (1977), Use of response surface methodology for rapid optimization of microbiological media, Journal of Applied Bacteriology, vol. 43, pp. 197-204.

3. Lee, S.L. and Chen, W.C. (1997), Optimization of medium composition for the production of glucosyltransferase by Aspergillus niger with response surface methodology, Enzyme and Microbial Technology, vol. 21, pp. 436-440.

4. Rahman, R.A., Illias, R.M., Nawawi, M.G.M., Ismail, A.F., Hassan, O., and Kamaruddin, K. (2004), Optimisation of growth medium for the production of cyclodextrin glucanotransferase from Bacillus stearothermophilus HR1 using response surface methodology, Process Biochemistry, vol. 39, pp. 2053-2060.

5. Ibrahim, H.M., Yusoff, W.M.W., Hamid, A.A., Illias, R.M., Hassan, O., and Omar, O. (2005), Optimization of medium for the production of $\beta$-cyclodextrin glucanotransferase using Central Composite Design (CCD), Process Biochemistry, vol. 40, pp. 753-758.

6. Chang, Y.N., Huang, J.C., Lee, C.C., Shih, I.L., and Tzeng, Y.M. (2002), Use of response surface methodology to optimize culture medium for the production of lovastatin by Monascus rubber, Enzyme and Microbial Technology, vol. 30, pp. 889-894.

7. Kendrick, A. and Ratledge, C. (1992), Desaturation of polyunsaturated fatty acids in Mucor circinelloides and the involvement of the novel membrane-bound malic enzyme, European Journal of Biochemistry, vol. 209, pp. 667-673.

8. Chaney, A.L. and Marbach, E.P. (1962), Modified reagents for determination of urea and ammonium, Clinical Chemistry, vol. 8, pp. 130-132.

9. Folch, J., Lees, M., and Sloane-Stanley, G.H. (1957), A simple method for the isolation of total lipids from animal tissues, Journal of Biological Chemistry, vol. 226, pp. 497-506. 
10. Myers, R.H. and Montgomery, D.C. (1995), Response surface methodology: process and product optimization using designed experiments. Wiley-Interscience.

11. Haalland, P.D. (1989), Experimental design in biotechnology, New York, Marcel Dekker, Inc.

12. Khuri, A.I. and Cornell, J.A. (1987), Response surfaces: design and analysis, New York, Marcel Dekker, Inc.

13. Stanbury, P.F., Whitaker, A., and Hall, S.J. (1984), Principles of fermentation technology, 2 (Ed.) Butterworth-Heinemann, Oxford. 